\title{
On Improvisation in Teaching and Teacher Education
}

\author{
JEAN-FRANÇOIS MAHEUX \\ Université du Québec à Montréal (Canada) \\ CAROLINE LAJOIE \\ Université du Québec à Montréal (Canada)
}

\section{On a New Requirement in Teacher Education}

Remember $\mathrm{Y} 2 \mathrm{~K}$ ? Back in those days, important changes took place in the way universities in Quebec were to conceive teacher education: "professional competencies" were supposed to become the backbone of our programs (see Lajoie \& Pallascio, 2001). One key idea we have drawn from this requirement is the concept of "knowing how to act in the moment." How could student-teachers be prepared to know how to deal with the unexpected? And not only to "know how", but indeed develop know-how, competencies to actually act in the moment and make the best - in terms of the subject matter - of surprising, unforeseen, startling events that sparkle in the everyday of teaching and learning? Even more: how can this "know how"be made part of "formal," intra muros, teacher education, and not only fall on the charge of practicum? Our answer: improvisation!

\section{On Improvisation and Role Play}

Placing improvisation at the heart of an undergraduate course in mathematics education is not the easiest thing to do. Our students themselves are quite puzzled when they 
come to class on the first day, and learn that every week there is going to be a role-play. Role-play involves staging a problematic situation with characters taking roles. It may be used to fulfill various objectives such as therapeutic objectives, personal and professional training objectives, or may be used as a pedagogical method (Mucchielli, 1983). The premise of role-play is to have persons such as students become active characters in a given situation. Why not have some students take the part of a teacher while others act as students, and improvise around a mathematical task, a students' question or production, the use of teaching material, and so on? Sounds good... but how is this going to work? Wouldn't they learn more about mathematics teaching and learning if theory was "thaught" and concrete examples of mathematical lessons or children's productions were presented for analysis? How are they going to learn mathematics teaching along the way? How can they improvise on teaching mathematics when this is what they come here to learn? Not to mention that arithmetic, the subject of that course, is often not their cup of tea: fractions? hand divisions? multiplication with decimals? Improvising on something you know well is one thing, but improvising with students on something you struggle with yourself?

We are not the first to believe that learning comes with doing, and not prior to it. Following our approach, students become actors in lessons and discussions about classroom issues instead of simply imagining or analysing these. We give such importance to improvisation in one our mathematics teaching courses because we, as educators of teachers, are interested in developing our students' kwowing-to act in the moment, and not only in developing their knowledge-about mathematics teaching and learning, as Mason and Spence (1999) would say:

knowing-to act when the moment comes requires more than having accumulated knowledge-about. It requires relevant knowledge to come to the fore so it can be acted upon. That is what knowing-to captures for us. (p.139)

These authors also suggest that intentional preparation benefits the bringing to mind 'in the moment' of possibility for action. It thus make sense to have the students experience various teaching situations and do so from the point of view of both the teacher, the student, and also as "observers." And not only experience, but also examine what comes out of improvisation so to prepare oneself, for example by identifying difficulties or alternative courses of action. Preparation, of course, also means to anticipate. Quite easily, role-play can be managed in such a way. Students can be given "roles" to prepare, then improvise with a partner (no script!) while others observe, and a discussion can then follow. But then again, why improvisation?

\section{On Improvisation and Complexity}

From the perspective of complexity, what is improvisation, might we ask? We started from a general definition, with the idea of doing something "in the moment", without a script or step-by-step preparation, and pretty much "in response to" one's immediate environment, inner feelings, and so on. Pretty much what we find in the Latin root of the word improvisation, improvisus, which signifies "unforeseen." And then we discovered a 
paper by Alfonso Montuori (2003) about "the complexity of improvisation and the improvisation of complexity" in which he stresses the importance of not reading improvisation as a deficiency (i.e. merely 'making do'), but rather as something fundamental to our existence in the world:

Improvisation might be said to serve at least a dual role [...allowing] us to adapt in our own way to complex environments, and [...] to express our own (inner) complexity through the performance of our interaction with the world. The concept of improvisation is, I believe, crucial to the existential reality of complexity [...because it] "involves a constant dialogic between order and disorder, tradition and innovation, security and risk (p. 245-246)

All this makes a lot of sense to us. After all, one of the key aspects of selforganization is the creation of order "at the edge of chaos" (Kauffman, 1995), where too much order leads to death, and too much chaos means the loss of all form of structure. Thinking about it, even in situations where survival is not at stake, "immediate coping is, in fact, the real 'hard work'" and constitutes "much of our mental and active life" (Varela, 1999, p. 18-19). It is thanks to the possibility and the necessity to improvise that constraints and possibility, structure and agency, can co-emerge in and as the lived life of our everyday, moment-to-moment, actions.

To get a better grasp on the idea, we take communication as an example. On the one hand, speech itself requires improvisation because of its processual nature: when we talk, we are addressing our own thinking, and not merely delivering words to signify preformed thought, but developing them with/in the talk which feeds back to itself, demanding constant adjustment (e.g. Denes \& Pinson, 1993). Quite evidently, the same goes for conversations: when addressee and addresser change role, they have to deal with unpredictable statements, and are at the same time under the obligation to respond, and to set up the next turn for the other (e.g. Bakhtin, 1984).

\section{On Teaching}

Needless to say, teaching, for us, has a lot to do with improvisation. This is the case not only because life is constant improvisation, but also in the sense of what it means to teach, and in our case: to teach mathematics. As we see it, teaching mathematics requires listening on the part of the teacher, and thus adaptation. ${ }^{1}$ Whether this listening is "for something," "to the students" or "with them" (Kieren, 1995) may of course affect the kind and the intensity of the improvisation, the act of teaching remains an opening to the unpredictable. Giving room for students' questions or explanations, inquiring on their reasoning or observations, asking them to explore, try out, come up with their own procedures or algorithms, improvisation takes place at least at some point in all of this.

Familiar to complexity-aware educators, there are perspectives on teaching which actually give a fundamental role to possibilities of adaptation. We read in this journal

${ }^{1}$ We write here about improvisation and teaching, but what an interesting topic would be the relation between learning and improvisation! 
about self-organizational pedagogy, for example, which "invites risks, nurtures improvisations, and cultivates transformations" (Laroche, Nicol \& Mayer-Smith, 2007, p. 74). More recently, we were reading here Crowell and Reid-Marr (2010) evoking something they call "emergent teaching" in which "magical and unanticipated" is to take place (p. 118). And of course, we know for example about the notion of enabling constraints (e.g. Davis \& Sumara, 2010) by means of which the teacher "define the field of play" so that learning can emerge as something never totally determined, or predictable. Is it too much to think that improvisation is key when teaching is conceptualized in such terms?

\section{On Classroom Improvisation}

In one of the first sessions of our course in didactique de l'arithmétique last term, we introduced to the students a short excerpt in which a teacher asks her students to present their solutions to the problem of sharing fairly five chocolate bars among four children. In the video, the following conversation takes place:

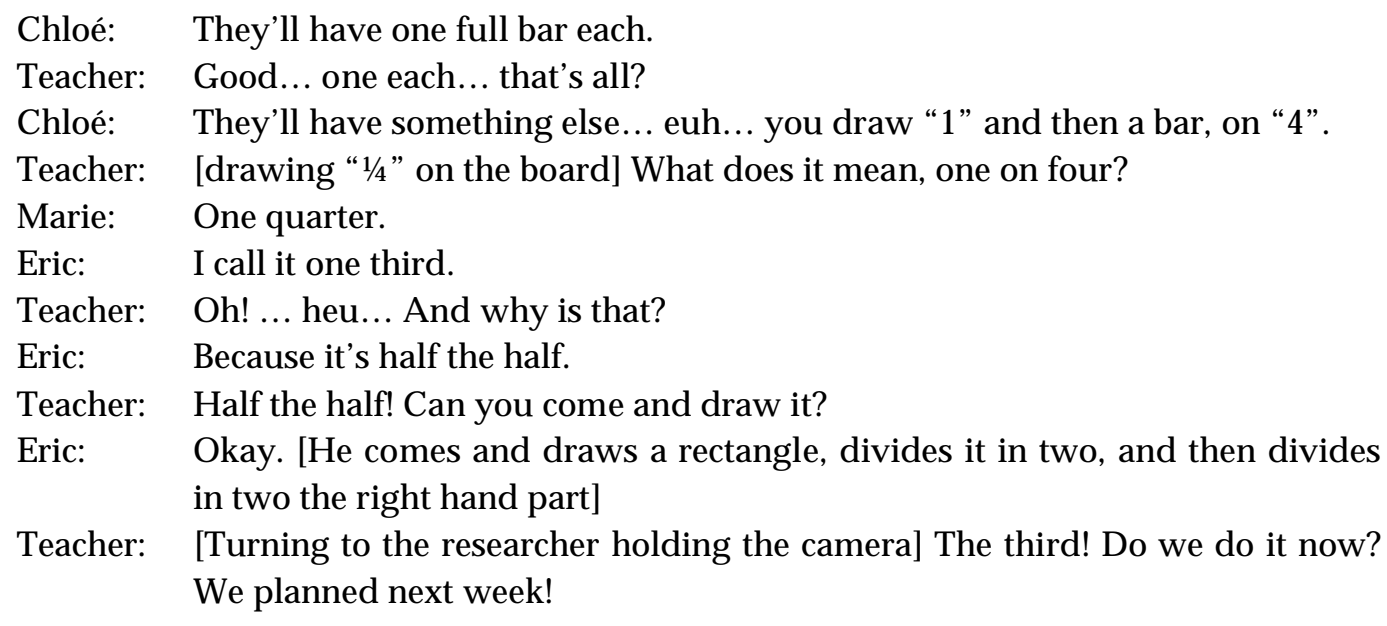

We like this fragment for many reasons, including the various forms of improvisation at play, and discuss it with our teacher-students. In not knowing what will come from the students, the teacher has to deal with expected "incomplete solutions" which may turn out to be "incomplete answers" once the student is asked to elaborate. There are also moments in which students' answers are so different from what she expects, she can't but be startled. And then the indecision (so nicely explicit in this excerpt), on whether or not a student's idea should be explored, and to what extent.

What also comes forth in this excerpt is how the teacher not only copes with the students answers, but does so in a way that brings about interesting mathematical activity on the part of the students. Asking them if something can be added, or explained, or represented, students keep offering their mathematical thinking. And the teacher, of course, keeps improvising on those developments. Her interventions are projective rather than of a normative or withdrawing type (DeBlois \& Maheux, 2005), drawing on and opening up students' mathematical activity. That is, if improvisation is 
obviously central to teaching, we realize that not all kinds of improvisations are equally fruitful, enriching or productive. Hence the importance to support student-teachers' development in such a matter... and we tell them.

\section{On Teacher Education}

In the lived life of most, if not all classrooms, teachers are confronted with the necessity to react in the here and now: There is not always time for deliberation, and teaching is often made of stop-gaps, even if reflection can take place before or after the action. As teacher educators, it seems to us that teacher training programs should somehow prepare the students to experience the necessity to improvise in the most fertile way... if not adopt fecund improvisation as a modus operandi!

Our undergraduate course Didactique de l'arithmétique au primaire is designed around ten different role-plays in which the students have to improvise... in an informed way, so to help the students develop mathematically. Typically, we begin by introducing the situation in which we want the students to improvise, and then give them about 30 minutes to prepare themselves in small groups (Figure 1 shows an example of such situation).

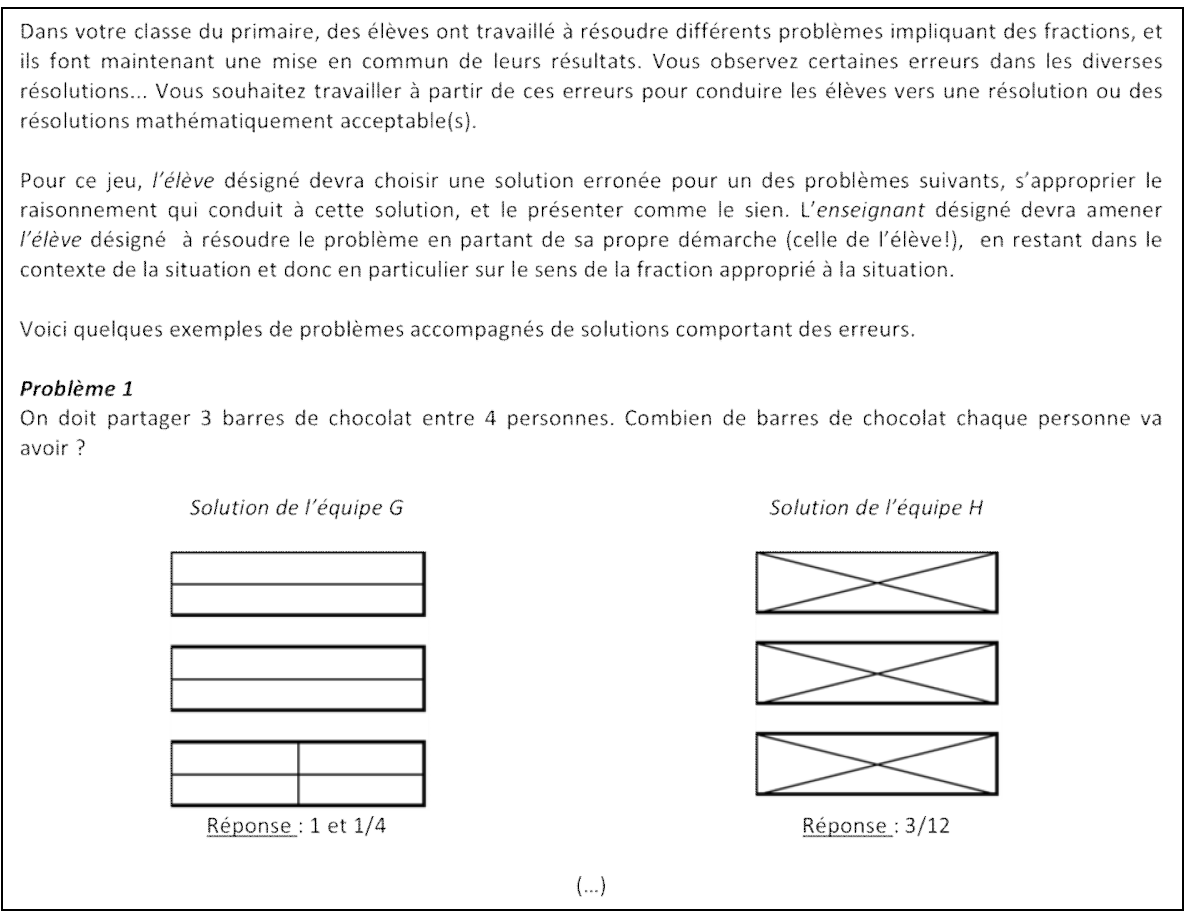

Figure 1. A situation involving students' productions on dividing 3 chocolates between 4 persons.

In the preparation time, students reflect on what might happen between the teacher and the student, not knowing beforehand who will play the role of a pupil or that of a teacher. To prepare themselves, they generally draw on an article they've read at home, and the analysis of pupils' productions related to the topic. Nonetheless, the role-plays often destabilize students from the onset because what first appeared to be simple soon 
confronts students with their own understanding of the mathematical concepts involved (for example, to deal with the errors in the students solution in Figure 1). This destabilization effect is intended, and helps the students engage in the preparation for role-play.

Based on what we observed in the preparation (while making sure everyone has a turn), we then pick groups at the time to go and play in front of the class, assigning them to roles of teachers and students. The groups choose which member is going to play. Since each group prepared separately, the students really have to improvise, and the goal is, for the "teacher" to work from the "pupil's" perspective (having him/her explain a solution, use a manipulative, reformulate, exemplify, and so on) in order to move his/her mathematical thinking forward. There is no script, and no specifically predefined end-point either. This is in part because in the group discussion which follows every sets of play, we want to engage with the students on the variety of possible interventions, and how they relate to one's intention and to what comes from the pupils. This also serves to reiterate our belief that improvisation is at the heart of teaching, as opposed to the idea that there might be one best way to teach this or that concept, or to address this or that student's question or production (as an already decided outcome might do). It allows us to reflect with the class on what happened, what might have been done, what could be done next, and so on, while keeping the questions open to the requirements of the situation in which they will encounter them in their own teaching.

\section{Improvisation for Research in Teacher Education}

What we call "informed improvisation" means a lot to us, and strongly resonates with our views on teaching and teacher education. It should be borne to mind, however, that we do not offer this as a "one-size fits-all" device for teacher preparation. As we see it, it is one of the possible ways to address the improvisational nature of teaching in a complex world. We keep it clear that we conceive the complexity of teacher education as irreducible, meaning that diversity must be nourished and encouraged (Maheux, 2011), for, as Waks (2011) puts it, the "emergence of novel training activities from unpredicted interactions among staff and teacher trainees" (p. 67, our emphasis).

This last observation is of particular importance because there is still, in the educational research community at large, an over dominant tendency to "find" the "best" way to teach this or that concept rather than value subjectivity, emotion, aesthetic, openness and uncertainty, even within complexivist thinking (e.g. Maheux, 2009). Improvisation is part of any moment in teaching, and the distinctions we make are whether we choose to embrace it or not, and to what extent. Same goes, we believe, for our theories on teaching and learning: all - one way or another - recognise the presence of unpredictability, but only few put it at the forefront, or take it as a point of departure. That is what we decided to do, end of the story. Or maybe not, it's yours to see! 


\section{References}

Bakhtin, M. (1984). Esthétique de la création verbale. Paris : Gallimard.

Crowell, S., \& Reid-Marr, D. (2010). The Non-Linear Nature of Emergent Teaching: A Multi-threaded Tale. Complicity: An International Journal of Complexity and Education 7, 2, 116-119.

Davis, B., \& Sumara, D. (2010). "If things were simple ...": complexity in education. Journal of Evaluation in Clinical Practice, 16(4), 856-860.

Denes, P., \& Pinson, E. (1993). The Speech Chain: The Physics and Biology of Spoken Language. 2nd ed. Worth Publishers.

Kauffman, S. (1995). At home in the Universe. The search for the laws of self-organization and complexity. New York: Oxford University Press.

Lajoie, C. \& Pallascio, R. (2001). Le jeu de rôle : une situation-problème en didactique des mathématiques pour le développement de compétences professionnelles, Actes du colloque des didacticiens et des didacticiennes des mathématiques (GDM), Montréal, 7- 9 mai 2001.

Laroche, L., Nicol, C. \& Mayer-Smith, J. (2007). New Venues for Science Teacher Education: Selforganizational Pedagogy on the Edge of Chaos. Complicity: An International Journal of Complexity and Education, 4(1), 69-83.

Maheux, J.F. (2009). Complicity or compliance? Complicity: An International Journal of Complexity and Education, 7(1), 89-97.

Maheux, J.F. (2011). Former à l'enseignement des maths au primaire : Petit éloge de l'artiste. In J. Proulx et al. (Eds) Actes du colloque Formation mathématique pour l'enseignement des mathématiques: pratiques, orientations et recherches. Montréal : PUQ.

Sawyer, K. (2003). Improvised Dialogues. London: Alex Publishing.

Varela, F.J. (1999). Ethical know-how: action, wisdom, and cognition. Standford : Standford University Press.

Waks, L. (2011). Teacher education programs as complex organizations. Complicity: An International Journal of Complexity and Education, 8 (1), 65-69.

DeBlois, L. et Maheux, J.F. (2005). When things don't go exactly as planned: Leveraging from student teachers' insights to adapted interventions and professional practice. Proceedings of the ICMI-Study15. Online: stwww.weizmann.ac.il/G-math/CMI/Deblois_LucieICMI15_prop.doc

Laroche, L., Nicol, C., \& Mayer-Smith, J. (2007). New Venues for Science Teacher Education: Selforganizational Pedagogy on the Edge of Chaos. Complicity: An International Journal of Complexity and Education, 4 (1), 69-83.

\section{About the Authors}

Jean-François Maheux is a Professor at the Université du Québec à Montréal. His research interests are in the day-to-day of researching, teaching and learning in mathematics education, mostly from the perspective of epistemology and ethics. Email at maheux.jean-francois@uqam.ca or visit http://math.uqam.ca/maheuxjf.

Caroline Lajoie is a Professor at the Université du Québec à Montréal. Her research interests are mainly concerned with pre-service teacher education in mathematics. Email at lajoie.caroline@uqam.ca or visit http://www.math.uqam.ca/_lajoie.

(C) Copyright 2011. The authors, JEAN-FRANÇOIS MAHEUX and CAROLINE LAJOIE, assign to the University of Alberta and other educational and non-profit institutions a non-exclusive license to use this document for personal use and in courses of instruction provided that the article is used in full and this copyright statement is reproduced. The authors also grant a non-exclusive license to the University of Alberta to publish this document in full on the World Wide Web, and for the document to be published on mirrors on the World Wide Web. Any other usage is prohibited without the express permission of the authors. 